\title{
Donor-derived 47, XXY in an unrelated cord blood transplant recipient
}

\author{
Kuniki Kawaguchi, Takayuki Nakamura, Masayuki Nohara, Satoko Koteda, Kei Nomura, Satoshi Morishige, Eijiro Oku, \\ Rie Imamura, Fumihiko Mouri, Ritsuko Seki, Koichi Osaki, Michitoshi Hashiguchi, Kohji Yoshimoto, Koji Nagafuji \\ and Takashi Okamura
}

\begin{abstract}
A 65-year-old Japanese male with therapy-related myelodysplastic syndrome was admitted for unrelated cord blood transplantation. A cord blood unit from a male donor was obtained from the Japan Cord Blood Bank Network. The patient then received a conditioning regimen consisting of fludarabine, intravenous busulfan, and total body irradiation. Successful engraftment was obtained. The bone marrow examination on day 28 revealed trilineage engraftment, and chimerism analysis by variable number of tandem repeat polymerase chain reaction confirmed complete donor chimerism. At that time, conventional cytogenetics of the bone marrow aspirate showed 20 out of 20 metaphases with the 47, XXY karyotype characteristic of Klinefelter syndrome. Klinefelter syndrome is the most common genetic cause of human male infertility with a reported prevalence of $0.1-0.2 \%$ in the general population. In Japan Cord Blood Bank Network, there is no informed consent from parents about the possibility that post-unrelated cord blood transplantation patient evaluation may reveal donor-origin inherited diseases including cytogenetic abnormality. It is desirable to have opportunities in Japan discussing whether parents will be notified of the possibility that post-unrelated cord blood transplantation evaluation may reveal donor-derived illness incidentally.
\end{abstract}

Keywords: Chromosomal abnormalities; Donor-derived; Cord blood; Hematopoietic stem cell; Transplantation

\section{Background}

The use of unrelated cord blood (CB) as a source of hematopoietic stem cells has been increasing in Japan. Indeed, more than a thousand unrelated cord blood transplantations (UCBTs) are performed annually in Japan (Japanese Cord Blood Bank Network, 2014). One of the distinct disadvantages of cord blood unit use is the lack of a significant clinical history from the donor. To compensate for this lack, the Japanese Cord Blood Bank Network screens the donor's parents for genetic diseases, screens placental and maternal blood for infectious diseases, and performs blood and HLA typing. In addition, the Japanese Cord Blood Bank Network has a mandatory quarantine period of 6 months so that units cannot be used until a minimal amount of adverse medical event data on the donor can be obtained (Moore et al. 2005).

The informed consent for cord blood donation is obtained from the parents and of course not from the fetus

\footnotetext{
* Correspondence: knagafuji@med.kurume-u.ac.jp

Department of Medicine, Division of Hematology and Oncology, Kurume University School of Medicine, 67 Asahi-machi, Kurume 830-0011, Japan
}

or infant. To confirm engraftment after UCBT and evaluate the status of the primary disease, cytogenetic analysis of bone marrow is performed routinely. These analyses identify indirectly the karyotype of donor cells. Here, we report the case of a UCBT recipient whose post-transplant karyotype analysis revealed 47, XXY.

\section{Case description}

A 65-year-old Japanese male was admitted to our hospital for UCBT in 2012.

In 2003, he was diagnosed with follicular lymphoma stage IVA, and treated with rituximab-containing chemotherapy resulting in a first complete remission (CR). His first relapse occurred in 2004 and treatment consisted of three courses of rituximab and the CHASE regimen (Ogura et al. 2003). His second relapse occurred in 2007 and treatment with rituximab, the CHASE regimen, and then autologous peripheral blood stem cell transplantation led to a third CR (Kamezaki et al. 2007). His third relapse occurred in 2009, and was treated with ${ }^{90}$ yttrium-ibritumomab-tiuxetan, obtaining a fourth CR.

\section{穴}


In 2012, routine blood examination revealed immature cells in the peripheral blood, and bone marrow examination confirmed the diagnosis of therapy-related myelodysplastic syndrome RAEB-1 with the abnormal karyotype of 45, XY, del5q, del7q, del12p, -13. His International Prognostic Scoring System (IPSS) score was Int-2 (Greenberg et al. 1997). A cord blood unit from a male donor was obtained from the Japan Cord Blood Bank Network, was mismatched at 2 HLA loci, contained $1.93 \times 10^{7} / \mathrm{kg}$ of nucleated cells, and contained $0.62 \times 10^{5} / \mathrm{kg}$ of CD34-positive cells. The patient then received a conditioning regimen consisting of fludarabine (30 $\mathrm{mg} / \mathrm{m}^{2}$ on days -7 to -2 ), intravenous busulfan (3.2 $\mathrm{mg} / \mathrm{kg}$ on days -6 to -3 ), and total body irradiation (4 Gy on day -2) (Takagi et al. 2010) as well as graft-versus-host disease (GVHD) prophylaxis consisting of intravenous tacrolimus $(0.02 \mathrm{mg} / \mathrm{kg} /$ day $)$ beginning on day -1 and short-term methotrexate on days 1,3 , and 6 $\left(5 \mathrm{mg} / \mathrm{m}^{2}\right)$. Engraftment was obtained. A neutrophil count of $>0.5 \times 10^{3} / \mathrm{L}$ and a platelet count of $>20 \times 10^{3} / \mathrm{L}$ were achieved on days 14 and 42, respectively. He developed acute GVHD grade II of the gut and was successfully treated with hydrocortisone. The bone marrow examination on day 28 revealed trilineage engraftment, and chimerism analysis by variable number of tandem repeat using the AmpFLSTR ${ }^{\bullet}$ SGM Plus ${ }^{\oplus}$ PCR Amplification Kit (Applied Biosystems) confirmed the establishment of complete donor chimerism. At that time, conventional cytogenetics of the bone marrow aspirate showed 20 out of 20 metaphases with 47, XXY (Figure 1). On day 130, peripheral blood examination revealed emergence of blasts, and on day 137, bone marrow examination showed recurrence of myelodysplastic syndrome. At that time, chimerism analysis revealed mixed chimerism of $64.4 \%$ donor origin, and conventional cytogenetics of the bone marrow aspirate showed 14 out of 16 metaphases with 47, XXY, and 2 out of 16 metaphases with 45, XY, -3, del5q, add7q, del12p, -13 , + mar. Gradually cytopenia worsened and the patient was treated conservatively.

\section{Discussion}

Klinefelter syndrome was first described in 1942 as an endocrine disorder characterized by small firm testes, gynecomastia, hypogonadism, and higher than normal concentrations of follicle-stimulating hormone (FSH) (Klinefelter et al. 1942). About $80 \%$ of cases are due to the congenital numerical chromosome aberration 47, XXY (Lanfranco et al. 2004). Klinefelter syndrome is the most common genetic cause of human male infertility with a reported prevalence of $0.1-0.2 \%$ in the general population, but many cases remain undiagnosed because of substantial variation in clinical presentation and insufficient professional awareness of the syndrome itself. Abramsky and Chapple calculated that $10 \%$ of expected

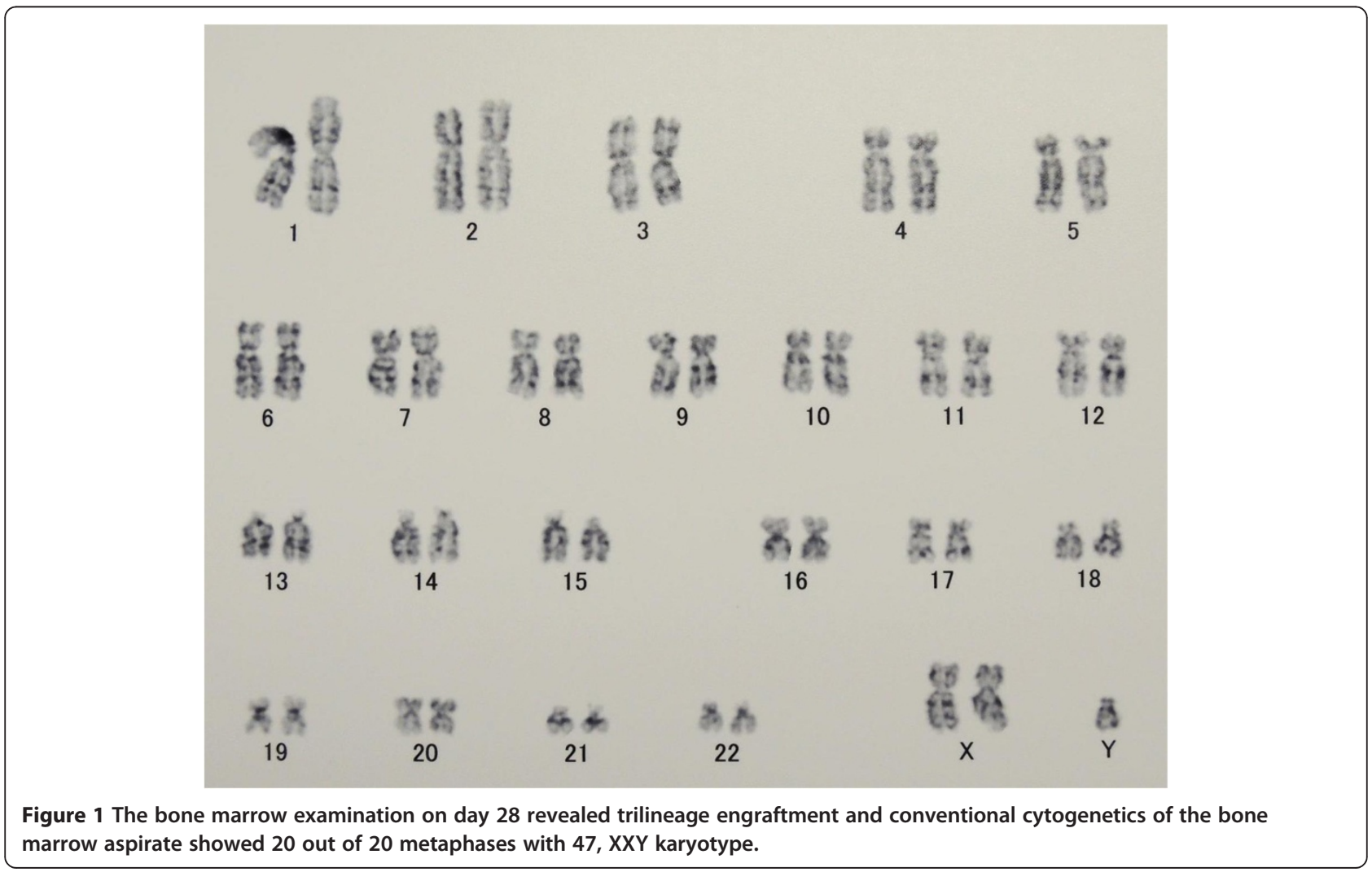


cases are identified prenatally and $26 \%$ are diagnosed in childhood or adult life because of hypogonadism, gynecomastia, or infertility, leaving 64\% undiagnosed (Abramsky and Chapple 1997). Indeed, Halaburda et al. reported diagnosis of Klinefelter syndrome in the donor after transplantation of allogeneic peripheral blood stem cells into a 35-year-old recipient with acute myelogenous leukemia from his 37-year-old HLA-identical brother (Halaburda et al. 2000). In Japan, more than a thousand UCBTs have been performed annually, and the prevalence of Klinefelter syndrome is supposed to be $0.1-0.2 \%$. A cytogenetic survey conducted in Japan on 14,835 liveborn infants (7608 males and 7227 females) showed that 93 infants (6.27 per 1000) had a major chromosome abnormality, and of these, seven male (0.92 per 1000 male) infants had a 47, XXY karyotype. Thus, UCBT from male donors with Klinefelter syndrome like ours seems to happen continuously. In the Japanese Cord Blood Network, mothers must provide informed consent whether or not they want to know their infectious disease screening results (Japanese Cord Blood Bank Network, 2014). However, early in the course of their pregnancies, most mothers have been checked for infectious diseases as part of a routine screening program in Japan. Notably, parents who provide informed consent are not told about the possibility that donor-origin inherited diseases including cytogenetic abnormalities may develop post-UCBT. The prognosis of these inherited diseases may range from very mild to dismal. Among them, Klinefelter syndrome is a disease that with early recognition and hormonal treatment of the disorder can be managed, and quality of life can be substantially improved (Mehta and Paduch 2012). PostUCBT, cytogenetic analysis of bone marrow is performed routinely. These analyses identify indirectly the karyotype of donor cells. Various types of constitutional abnormalities of karyotype have been reported to be transmitted after allogeneic hematopoietic stem cell transplantation as shown in Table 1 (Graze et al. 1977; Becher et al. 1986; Kuffel et al. 1991; Barquinero et al. 1995; Halaburda et al. 2000; Moore et al. 2005; Manola et al. 2006; Ismail et al. 2007; Balci et al. 2008; Frey et al. 2008; Consoli et al. 2011). All donors with Down syndrome were identified before stem cell donations as the manifestations of Down syndrome were evident. On the contrary, most donors with numerical abnormalities of sex chromosomes were diagnosed after transplantation; it means the manifestations of numerical abnormalities of sex chromosomes were varying much and post-transplant chromosomal

Table 1 Reported cases of donor-derived chromosomal abnormalities in recipients with allogeneic stem cell transplantations

\begin{tabular}{|c|c|c|c|c|c|c|}
\hline Type of transplantation & Donor type & Donor age & Donor sex & Chromosomal abnormalities & $\begin{array}{l}\text { Timing of the } \\
\text { diagnosis }\end{array}$ & References \\
\hline BMT & $\mathrm{R}$ & 29 & M & $46, X Y, t(18 q+; 22 q-)$ & Before transplant & Graze et al. 1977 \\
\hline BMT & R & 28 & F & $47, X X X$ & After transplant & Becher et al. 1986 \\
\hline BMT & $\mathrm{R}$ & 19 & $\mathrm{~F}$ & $45, X X ;$ rob t $(14 ; 14)$ & After transplant & Becher et al. 1986 \\
\hline BMT & R & NA & NA & $47, X X Y$ & NA & Kuffel et al. 1991 \\
\hline BMT & R & NA & NA & $47, X X Y$ & NA & Kuffel et al. 1991 \\
\hline BMT & $\mathrm{R}$ & NA & NA & $45, X / 46, X X$ & NA & Kuffel et al. 1991 \\
\hline BMT & R & NA & NA & $46, X X / 47, X X,+$ mar & NA & Kuffel et al. 1991 \\
\hline BMT & R & 13 & F & Down syndrome & Before transplant & Barquinero et al. 1995 \\
\hline BMT & R & 26 & M & Down syndrome & Before transplant & Barquinero et al. 1995 \\
\hline BMT & $\mathrm{R}$ & 23 & $\mathrm{~F}$ & Down syndrome & Before transplant & Barquinero et al. 1995 \\
\hline BMT & $\mathrm{R}$ & 17 & $\mathrm{~F}$ & Down syndrome & Before transplant & Barquinero et al. 1995 \\
\hline BMT & R & 25 & $\mathrm{~F}$ & $47, X X X$ & After transplant & Barquinero et al. 1995 \\
\hline BMT & $\mathrm{R}$ & 48 & $\mathrm{~F}$ & $47, X X X$ & After transplant & Barquinero et al. 1995 \\
\hline PBSCT & $\mathrm{R}$ & 37 & M & $47, X X Y$ & After transplant & Halaburda et al. 2000 \\
\hline CBT & U & 0 & F & $47, X X X$ & After transplant & Moore et al. 2005 \\
\hline NA & $\mathrm{R}$ & 2.5 & $\mathrm{~F}$ & $45, X / 46, X X$ & After transplant & Manola et al. 2006 \\
\hline NA & $\mathrm{R}$ & 54 & $\mathrm{~F}$ & $45, X / 46, X X$ & After transplant & Manola et al. 2006 \\
\hline BMT & $\mathrm{R}$ & 23 & M & $46, X X / 46, X X, \operatorname{dic}(Y ; 22)(p 11.2 ; p 11.2)$ & After transplant & Ismail et al. 2007 \\
\hline BMT \& CBT & $\mathrm{R}$ & 11 month & M & $47, X X Y$ & Before transplant & Balci et al. 2008 \\
\hline BMT & $U$ & 26 & M & $47, X Y,+8$ & After transplant & Frey et al. 2008 \\
\hline BMT & U & NA & M & $45, X Y, \operatorname{der}(14 ; 21)(q 10 ; q 10)$ & After transplant & Consoli et al. 2011 \\
\hline
\end{tabular}


analysis of recipients revealed these numerical abnormalities. In the setting of UCBT, as far as we know, only one case of the donor-derived 47, XXX karyotype has been reported in the literature (Moore et al. 2005). The Netcord and Foundation for Accreditation of Cellular Therapy (NETCORD-FACT) international standards for cord blood collection, banking, and release for administration recommends in the informed consent section that the cord blood bank "maintain linkage for the purpose of notifying the infant donor's mother or family and/or her physician of communicable or genetic diseases, whenever possible" (International Standards for Cord Blood Collection, Banking, and Release for Administration 2013). On the contrary, in Japan Cord Blood Banking Network, there is no informed consent from parents about the possibility that post-UCBT patient evaluation may reveal donor-origin inherited diseases including cytogenetic abnormality. It is a matter of great delicacy. Some parents may want to know their child's abnormality, and others may not (Sugarman et al. 2002). It is desirable to have opportunities in Japan discussing whether parents will be notified of the possibility that post-UCBT evaluation may reveal donor-derived illness incidentally.

\section{Conclusions}

We described donor-derived cytogenetic abnormalities of 47, XXY in the recipient of UCBT. It is desirable to have opportunities in Japan discussing whether parents will be notified of the possibility that post-UCBT evaluation may reveal donor-derived illness incidentally.

\section{Consent}

Written informed consent was obtained from the patient for the publication of this report and any accompanying images.

\section{Competing interests}

There is no conflict of interest in this manuscript.

\section{Authors' contributions}

All took care of the patient. KK and KN wrote the manuscript. All authors read and approved the final manuscript.

Received: 18 January 2014 Accepted: 3 February 2014

Published: 6 February 2014

\section{References}

Abramsky L, Chapple J (1997) 47, XXY (Klinefelter syndrome) and 47, XYY: estimated rates of and indication for postnatal diagnosis with implications for prenatal counselling. Prenat Diagn 17(4):363-368

Balci YI, Turul T, Daar G, Anak S, Devecioglu O, Tezcan I, Cetinkaya DU (2008) Hematopoietic stem cell transplantation from a donor with Klinefelter syndrome for Wiskott-Aldrich syndrome. Pediatr Transplant 12(5):597-599

Barquinero J, Witherspoon R, Sanders J, Horowitz MM, Montuoro A, Patton DF, Bacigalupo A, Abecasis MM, Miale T, Rozman C et al (1995) Allogeneic marrow grafts from donors with congenital chromosomal abnormalities in marrow cells. Br J Haematol 90(3):595-601

Becher R, Mahmoud HK, Schaefer UW, Schmidt CG (1986) Transplantation of bone marrow with constitutional chromosomal anomalies. Cytogenetic studies and clinical implications. Blut 53(4):341-346
Consoli C, Leotta S, Tambe L, Di Marco AL, Avola G, Camuglia MG, Di Mercurio S, Poidomani M, Milone G (2011) Inadvertent transplantation of haematopoietic stem cells carrying constitutional Robertsonian translocation from an apparently normal donor to an AML patient: a case report. Bone Marrow Transplant 46(9):1278-1279

Frey NV, Leid CE, Nowell PC, Tomczak E, Strauser HT, Kasner M, Goldstein S, Loren A, Stadtmauer E, Luger S, Hexner E, Hinkle J, Porter DL (2008) Trisomy 8 in an allogeneic stem cell transplant recipient representative of a donor-derived constitutional abnormality. Am J Hematol 83(11):846-849

Graze P, Sparkes R, Como R, Gale RP (1977) Hematopoietic engraftment following transplantation of bone marrow cells carrying a Philadelphia (Ph')-like chromosome. Am J Hematol 3:137-142

Greenberg P, Cox C, LeBeau MM, Fenaux P, Morel P, Sanz G, Sanz M, Vallespi T, Hamblin T, Oscier D, Ohyashiki K, Toyama K, Aul C, Mufti G, Bennett J (1997) International scoring system for evaluating prognosis in Myelodysplastic syndromes. Blood 89(6):2079-2088

Halaburda K, Bieniaszewska M, Brozek I, Limon J, Hellmann A (2000) Diagnosis of Klinefelter syndrome in the donor after peripheral blood stem cell transplantation. Bone Marrow Transplant 25(4):461

International Standards for Cord Blood Collection, Banking, and Release for Administration (2013) http://www.factweb.org/forms/store/ProductForm Public/search?action=1\&Product_productNumber $=627$

Ismail S, Qubbaj W, Kilani M, Hijazi M, Abdelnour A, Al-khateeb M, Awidi A (2007) Successful bone marrow transplantation for treatment of chronic myeloid leukemia from a donor with mosaic Klinefelter syndrome. Int J Hematol 86(3):287-288

Japanese Cord Blood Bank Network (2014) https://www.j-cord.gr.jp/

Kamezaki K, Kikushige Y, Numata A, Miyamoto T, Takase K, Henzan H, Aoki K, Kato K, Nonami A, Kamimura T, Arima F, Takenaka K, Harada N, Fukuda T, Hayashi S, Ohno Y, Eto T, Harada M, Nagafuji K (2007) Rituximab does not compromise the mobilization and engraftment of autologous peripheral blood stem cells in diffuse-large B-cell lymphoma. Bone Marrow Transplant 39(9):523-527

Klinefelter HF, Reifenstein EC, Albright F (1942) Syndrome characterized by gynecomastia, aspermatogenesis without a-Leydigism, and increased excretion of follicle-stimulating hormone. J Clin Endocrinol 2(11):615-627

Kuffel DG, Schultz CG, Ash RC, Dewald GW (1991) Normal cytogenetic values for bone marrow based on studies of bone marrow transplant donors. Cancer Genet Cytogenet 55(1):39-48

Lanfranco F, Kamischke A, Zitzmann M, Nieschlag E (2004) Klinefelter's syndrome. Lancet 364(9430):273-283

Manola KN, Sambani C, Karakasis D, Baltathakis I, Zoumbos N, Symeonidis A (2006) Allogeneic stem cell transplantation from donors with mosaic Turner syndrome. Bone Marrow Transplant 38(5):385-386

Mehta A, Paduch DA (2012) Klinefelter syndrome: an argument for early aggressive hormonal and fertility management. Fertil Steril 98(2):274-283

Moore T, Campbell KJ, Feig SA (2005) Stem cells carrying abnormal karyotype engraft after cord blood stem cell transplant. J Pediatr Hematol Oncol 27(2):118-119

Ogura M, Kagami Y, Taji H, Suzuki R, Miura K, Takeuchi T, Morishima Y (2003) Pilot phase $1 / /$ study of new salvage therapy (CHASE) for refractory or relapsed malignant lymphoma. Int J Hematol 77(5):503-511

Sugarman J, Kurtzberg J, Box TL, Horner RD (2002) Optimization of informed consent for umbilical cord blood banking. Am J Obstet Gynecol 187(6):1642-1646

Takagi S, Ota Y, Uchida N, Takahashi K, Ishiwata K, Tsuji M, Yamamoto H, Asano-Mori Y, Matsuno N, Masuoka K, Wake A, Miyakoshi S, Ohashi K, Taniguchi S (2010) Successful engraftment after reduced-intensity umbilical cord blood transplantation for myelofibrosis. Blood 116(4):649-652

doi:10.1186/2193-1801-3-72

Cite this article as: Kawaguchi et al:: Donor-derived 47, XXY in an unrelated cord blood transplant recipient. SpringerPlus 2014 3:72. 